\title{
Hepatogastric fistula: a rare complication of pyogenic liver abscess
}

\author{
Venkata Srinivas Gandham, ${ }^{1}$ Biju Pottakkat, ${ }^{1}$ Lakshmi C Panicker, ${ }^{2}$ Ranjit Vijaya Hari ${ }^{3}$
}

${ }^{1}$ Department of Surgical Gastroenterology, JIPMER Puducherry, India ${ }^{2}$ Department of Medical Gastroenterology, SUT Hospital, Thiruvananthapuram, Kerala, India ${ }^{3}$ Department of Surgical Gastroenterology, SUT Hospital, Thiruvananthapuram, Kerala, India

\section{Correspondence to} Dr Biju Pottakkat, bijupottakkat@rediffmail.com

Accepted 30 June 2014

\section{CrossMark}

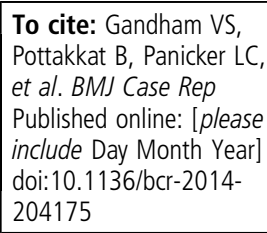

\section{SUMMARY}

Hepatogastric fistula is very rare. We report a case of hepatogastric fistula as a complication of pyogenic liver abscess. A 40-year-old man presented with upper abdominal pain and high-grade fever of 2 weeks. Evaluation revealed multiple liver abscesses. On an empirical diagnosis of pyogenic liver abscess, he was treated with antibiotics. During hospital stay he developed intermittent large quantity bilious vomiting. Gastroduodenoscopy and contrast-enhanced CT of the abdomen showed rupture of left lobe liver abscess into the stomach. As expectant management failed to resolve the abscess, endoscopic retrograde papillotomy and stenting of common bile duct was performed. After endoscopic stenting, symptoms subsided. Imaging repeated after 2 weeks of endoscopic stenting showed resolving abscess. He was discharged and is doing well on regular follow-ups. We conclude that hepatogastricfistula can be managed by endoscopic stenting as bile flow through the stent hastens resolution and healing of the fistula.

\section{BACKGROUND}

Hepatogastric fistula is a very rare complication of liver abscess. There are no guidelines for the diagnosis and management of this condition. ${ }^{1}$ We report a rare case of hepatogastric fistula as a complication of pyogenic liver abscess.

\section{CASE PRESENTATION}

A 40-year-old man presented with upper abdomen pain and high-grade fever of 2 weeks duration. $\mathrm{He}$ was an alcoholic. On examination there was tender hepatomegaly. Laboratory studies showed leukocytosis with white cell count of $14000 / \mathrm{mm}^{3}$ (reference range $\left.4000-11000 / \mathrm{mm}^{3}\right)$. His liver function tests were normal (total bilirubin $1.2 \mathrm{mg} / \mathrm{dL}$ (normal reference range 0.4 to $1.2 \mathrm{mg} / \mathrm{dL}$ ), direct bilirubin $0.4 \mathrm{mg}$ $\mathrm{dL}$ (normal reference range 0.1 to $0.4 \mathrm{mg} / \mathrm{dL}$ ), serum glutamic oxaloacetic transaminase $28 \mathrm{IU} / \mathrm{L}$ (normal reference range $0-40 \mathrm{IU} / \mathrm{L}$ ), serum glutamic pyruvic transaminase $32 \mathrm{IU} / \mathrm{L}$ (normal reference range 0$45 \mathrm{IU} / \mathrm{L})$ and serum alkaline phosphatase $132 \mathrm{IU} / \mathrm{L}$ (normal reference range 30-125 IU/L)). Ultrasonography of the abdomen was suggestive of multiple liver abscesses and altered echo texture of liver parenchyma. There was no risk factor for multiple abscesses identified. Based on a provisional diagnosis of pyogenic liver abscess, he was treated with ciprofloxacin $200 \mathrm{mg} /$ intravenous/12th hourly and metronidazole $500 \mathrm{mg} /$ intravenous $/ 8$ th hourly. The pus culture revealed Klebsiella pneumonia and antibiotic was changed to cefoperazone and sulbactum $2 \mathrm{~g}$ /intravenous/12th hourly which was continued for 5 days. Fever persisted and 5 days after admission he

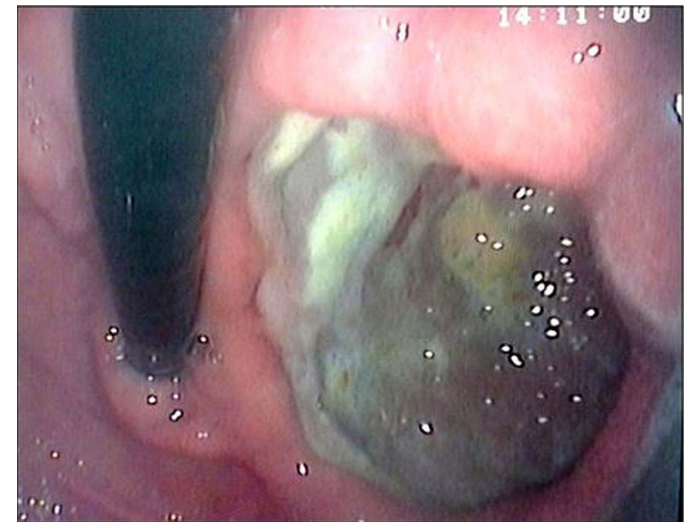

Figure 1 Gastroduodenoscopy image showing the fistulous opening of the hepatogastric fistula in the lesser curvature of the stomach.

developed intermittent large-quantity bilious vomiting. Gastroduodenoscopy showed large pool of bile in the stomach and excavating ulcer on the lesser curvature of the stomach (figure 1). Biopsy of the ulcer showed necrotic tissue with inflammatory exudates. There was no evidence of malignancy. He was then evaluated with contrast enhanced CT (CECT) abdomen with oral contrast. It showed rupture of liver abscess which was located in segment 2 and segment 3, into the stomach. Air and oral contrast was seen in the liver abscess (figure 2A, B). There were multiple small abscesses in both lobes of the liver. There were no gall stones or any other pathology identified on imaging. Expectant management with nil by mouth, proton pump inhibitors and broad spectrum antibiotics failed. He continued to have intermittent large-quantity bilious vomiting.

\section{INVESTIGATIONS}

Ultrasonography, gastroduodenoscopy and contrastenhanced CT of the abdomen were performed.

\section{TREATMENT}

Endoscopic retrograde cholangiopancreatography, papillotomy, stenting of common bile duct and antibiotics.

\section{OUTCOME AND FOLLOW-UP}

There was no pathology in the common bile duct on cholangiography. After endoscopic stenting, the patient continued to be on antibiotics for 5 days. His fever and vomiting subsided. CECT abdomen after 2 weeks of endoscopic stenting showed decrease in size of the abscess (figure 3). His follow-up gastroduodenoscopy at 4 weeks showed only a small $2 \mathrm{~cm}$ residual ulcer. There was no bile in the stomach. His stent in common bile duct was 

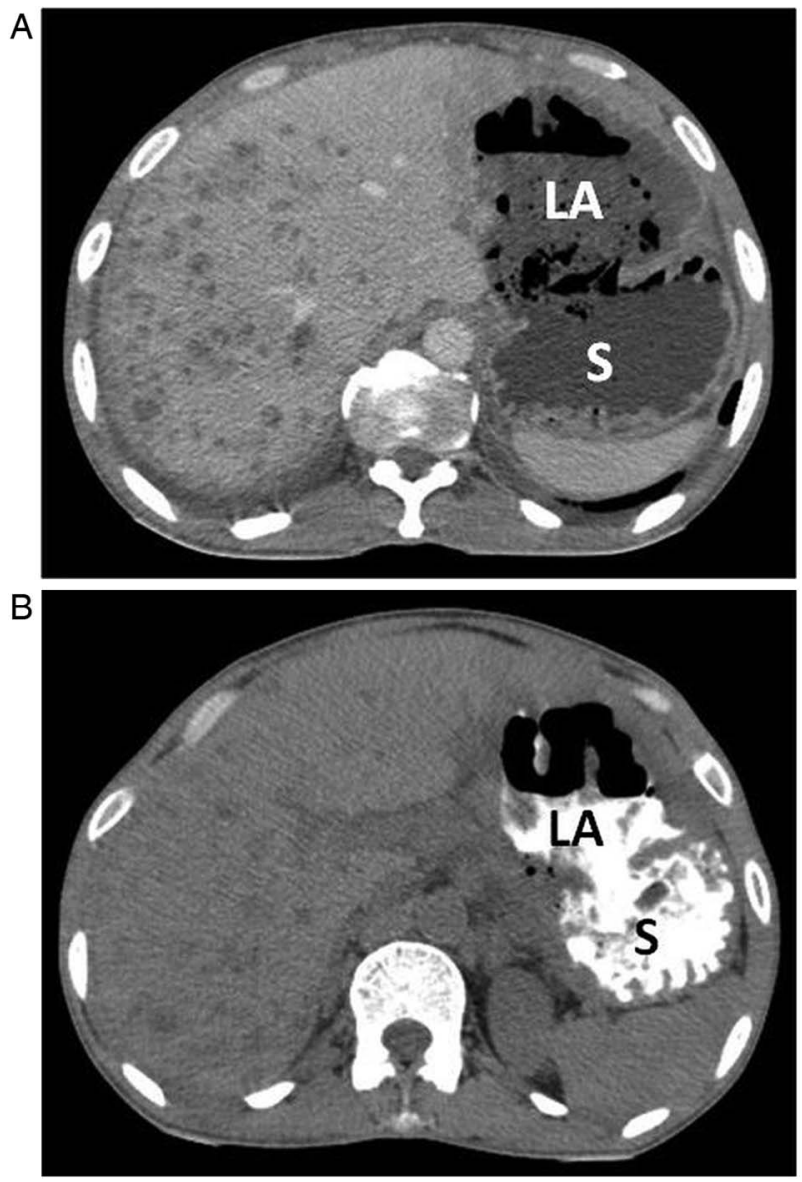

Figure $2 \mathrm{CT}$ images of the abdomen. (A) Abscess in the left lobe of liver communicating with the stomach. (B) Oral contrast in the stomach entering the abscess cavity in the left lobe of the liver. LA, liver abscess; S, stomach.

removed after 8 weeks of stenting. He is doing well on last follow-up.

\section{DISCUSSION}

Hepatogastric fistula is an extremely rare internal fistula which develops between the biliary systems of the liver and the stomach. There are only few case reports of hepatogastric

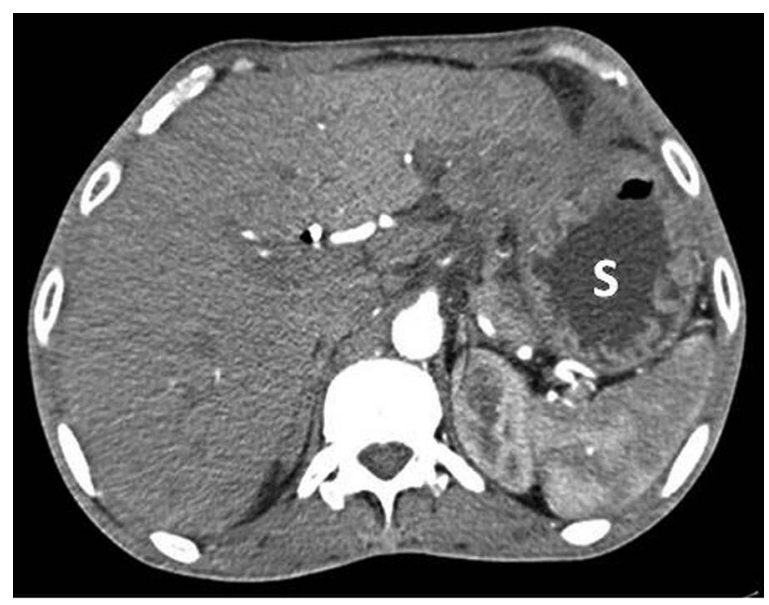

Figure 3 CT image of the abdomen showing resolution of abscess after 2 weeks of stenting of the common bile duct. S, stomach. fistula. It occurs as a rare complication of liver abscess due to rupture of the abscess into the stomach. It was described following rupture of liver abscess after transarterial embolisation or following radiotherapy for hepatocellular carcinoma $(\mathrm{HCC})^{2} 3$ liver abscess after percutaneous radiofrequency thermal ablation of HCC, amoebic liver abscess ${ }^{4}{ }^{5}$ or pyogenic liver abscess. ${ }^{6} 7$ It has also been described after iatrogenic injury of the stomach following percutaneous catheter drainage of liver abscess. ${ }^{8}$ Hepatogastric fistula is created by metal stent placement to decompress an obstructed biliary system in case of benign or malignant biliary obstruction. ${ }^{9}$ It has also been reported following direct infiltration of stomach by HCC. In the literature, we encountered only two case reports of hepatogastric fistula developed as a complication of rupture of pyogenic liver abscess. ${ }^{6}$

First case report was that of a 44-year-old man who was admitted with fever and abdomen pain. ${ }^{6} \mathrm{He}$ had solitary liver abscess in segment 2 of the liver of size $5.5 \mathrm{~cm}$. With provisional diagnosis of pyogenic liver abscess, usual antibiotics against pyogenic bacteria were initiated although the cultures were negative. After 6 days, the authors noticed that the abscess had drained through a spontaneous fistula into the stomach which was confirmed with imaging. The outcome was good and the patient was discharged. The authors had emphasised the need for early drainage to prevent such complications. Unlike our patient, this patient did not have intermittent large bilious vomiting; so he probably did not require any further intervention.

Second case report was that of a 77-year-old woman who was admitted with fever and headache. ${ }^{7}$ She was diagnosed to have bacterial meningitis and sepsis due to K. pneumonia and a cystic lesion in the liver measuring $13 \mathrm{~cm}$ in diameter in the left lobe. After treatment with antibiotics, her signs of infection subsided and the hepatic lesion decreased in size. She later developed gastric fistula and an increase in size of the liver lesion was noticed. With a suspicion of invasive biliary cystadenocarcinoma, she underwent hepatic and gastric resection. Specimen pathology suggested a pyogenic liver abscess complicated by gastric fistula. Probably early drainage and accurate diagnosis would have prevented a complication of the abscess and an extensive surgery. This further emphasises the need for early drainage of liver abscess and accurate diagnosis of hepatogastric fistula.

Unlike the above reported cases of solitary pyogenic liver abscesses, our patient had multiple liver abscess and probably the confluencing of the abscesses in segment 2 might have formed a large abscess with subsequent rupture into the stomach.

Hepatogastric fistulae was manifested by hematemesis or detected by imaging, in previous reported cases. But in our patient, large voluminous bilious vomiting was the presentation. Gastroduodenoscopy and CECT of the abdomen with oral contrast are the investigations of choice. Gastroduodenoscopy will show the area of direct involvement of the stomach. It can also be helpful in diagnosing whether the fistula is secondary to malignant aetiology in the stomach and liver or not. CECT of the abdomen also helps in characterising and localising the liver lesion. Direct communication between abscess and gastric lumen can be demonstrated and presence of air along with oral contrast in the abscess is confirmatory. Thus development of hepatogastric fistula should be suspected in a patient with liver abscess if there is large voluminous biliary vomiting. As bile flows through the path of least resistance, biliary system may be preferentially drained through the hepatogastric fistula into the stomach instead of the common bile duct (CBD) and ampulla. This high output of internal biliary fistula prevents its spontaneous closure. 
As described in previous case reports, non-operative management strategies include treatment with broad-spectrum antibiotics and proton pump inhibitors. Angioembolisation is recommended if there is hematemesis. ${ }^{2} 10$ Operative strategies include open drainage of abscess with excision of fistula and en bloc resection of the involved portions of the stomach and the liver. Operative strategies are recommended in hepatogastric fistula with HCC or if fistula fails to heal by conservative management. ${ }^{1}$ The main cause of failure of expectant management in our patient was high output internal biliary fistula. Hence

\section{Patient's perspective}

Avoiding an open surgery resulted in very high satisfaction levels for the patient.

\section{Learning points}

- Hepatogastric fistula as a complication of pyogenic liver abscess is very rare.

- The development of hepatogastric fistula should be suspected in a patient with liver abscess if there is large voluminous bilious vomiting.

- Hepatogastric fistula can be managed by endoscopic stenting as bile flow through the stent hastens resolution and healing of the fistula.

- Improper management of hepatogastric fistula can result in morbidity and mortality. endoscopic papillotomy and stenting of the CBD was performed. Endoscopic stenting of CBD, a strategy followed in the management of external biliary fistulas, may help in the closure of the fistula and hasten recovery as was described in this case. Hepatogastric fistula was associated with high morbidity ${ }^{7}$ and mortality ${ }^{2} 37$ in previous reported cases.

Competing interests None.

Patient consent Obtained.

Provenance and peer review Not commissioned; externally peer reviewed.

\section{REFERENCES}

1 Singh M, Kumar L, Kumar L, et al. Hepatogastric fistula following amoebic liver abscess: an extremely rare and difficult situation. OA Case Rep 2013;2:38.

2 Wang $\mathrm{CY}$, Leung SW, Wang JH, et al. Delayed spontaneous hepatogastric fistula formation following transcatheter arterial embolisation and radiotherapy for hepatocellular carcinoma. Br J Radiol 2009;82:e105-7.

3 Park H, Kim SU, Choi J, et al. Hepatogastric fistula caused by direct invasion of hepatocellular carcinoma after transarterial chemoembolization and radiotherapy. Korean J Hepatol 2010;16:401-4.

4 Falco A, Orlando D, Sciarra R, et al. A case of biliary gastric fistula following percutaneous radiofrequency thermal ablation of hepatocellular carcinoma. World $\mathrm{J}$ Gastroenterol 2007;13:804-5.

5 Budhiraja S, Dhatt GS, Babra RS. Hepatogastric fistula in a pediatric patient. Pediatr Surg Int 2006;22:853-5.

6 Monge-Fresse AS, Siriez JY, Bricaire F. Spontaneous fistulisation of a liver abscess into the stomach. Neth J Med 2007;65:456-7.

7 Yasuyuki T, Kenji O, Naoko Y, et al. Pyogenic liver abscess complicated by gastric fistula and bacterial meningitis. Nihon Shokakibyo Gakkai Zasshi 2007; 104:1512-18.

8 Kumar R, Sundar S, Sharma $\mathrm{P}$, et al. Conservative management of liver abscess complicated by hepatogastric fistula. Dig Liver Dis 2011;43:752-3.

9 Mistry JH, Varma V, Mehta N, et al. Percutaneous transhepatichepaticogastrostomy for portal biliopathy: a novel approach. Trop Gastroenterol 2012;33:140-3.

10 Sayana H, Yousef O, Clarkston WK. Massive upper gastrointestinal hemorrhage due to invasive hepatocellular carcinoma and hepatogastric fistula. World J Gastroenterol 2013;19:7472-5.

Copyright 2014 BMJ Publishing Group. All rights reserved. For permission to reuse any of this content visit

http://group.bmj.com/group/rights-licensing/permissions.

BMJ Case Report Fellows may re-use this article for personal use and teaching without any further permission.

Become a Fellow of BMJ Case Reports today and you can:

- Submit as many cases as you like

- Enjoy fast sympathetic peer review and rapid publication of accepted articles

- Access all the published articles

- Re-use any of the published material for personal use and teaching without further permission

For information on Institutional Fellowships contact consortiasales@bmjgroup.com

Visit casereports.bmj.com for more articles like this and to become a Fellow 